\title{
Globalização e espaços públicos: A não regulação como estratégia de hegemonia global
}

Globalization and Public Spaces: Non-regulation as a Strategy of Global

Hegemony

Globalisation et espaces publics: La non-régulation comme stratégie

d'hégémonie globale

\section{Leonardo Avritzer}

\section{(2) OpenEdition}

\section{Journals}

Edição electrónica

URL: http://journals.openedition.org/rccs/1270

DOI: $10.4000 /$ rccs. 1270

ISSN: 2182-7435

\section{Editora}

Centro de Estudos Sociais da Universidade de Coimbra

\section{Edição impressa}

Data de publição: 1 Outubro 2002

Paginação: 107-121

ISSN: 0254-1106

\section{Refêrencia eletrónica}

Leonardo Avritzer, «Globalização e espaços públicos: A não regulação como estratégia de hegemonia global », Revista Crítica de Ciências Sociais [Online], 63 | 2002, colocado online no dia 01 outubro 2012, criado a 19 abril 2019. URL : http://journals.openedition.org/rccs/1270 ; DOI : 10.4000/rccs.1270 


\title{
Globalização e espaços públicos: A não regulação como estratégia de hegemonia global
}

\begin{abstract}
Este artigo tem como objetivo tratar o recente processo de globalização do ponto de vista da relação entre regulação e emancipação. A minha tese principal será que o processo de globalização muda a relação entre essas duas categorias e exige a introdução de um terceiro elemento que denominarei de não-regulação. O meu argumento não é o de que a não regulação constitui uma característica completamente nova na modernidade e sim de que a forma como a hegemonia no espaço político globalizado ocorre no começo do século XXI consiste em uma combinação entre super-regulação e não regulação que adquire características completamente novas. A segunda questão que será tratada neste trabalho é: em que medida os novos espaços públicos globais que estão surgindo na modernidade tardia podem fazer frente a esses espaços globais não regulados.
\end{abstract}

1. O recente processo de globalização é um processo desigual que se desdobra de forma diferenciada nos campos econômico, político e cultural (Santos, 2001; Robertson, 2000). As assimetrias desse processos estão ligadas ao fato de que nem todos os elementos e as forças nele envolvidas se globalizam ao mesmo tempo, provocando formas diferenciadas de globalização das diversas entidades econômicas e instituições internacionalizadas. Assim, ao mesmo tempo que nós temos algumas entidades econômicas operando ao nível do sistema mundial, como as chamadas empresas transnacionais, nós temos também um forte presença de forças locais nas economias dos Estados nacionais recentemente globalizados. ${ }^{1}$ Da mesma maneira, assim como nós temos hoje em dia a existência de forças políticas transnacionais, tais como, os diferentes fóruns e conferências das Nações Unidas, a capacidade de organizações não governamentais de atuarem a nível internacional

\footnotetext{
${ }^{1}$ Hirst e Thompson foram os autores que mostraram essa tensão com maior clareza. Segundo os autores, a maior parte das empresas transnacionais ainda opera tendo como forte referência o espaço de certas economias nacionais (Hirst e Thompson, 1995).
} 
e um conjunto de instituições multilaterais com capacidade de influenciar decisivamente os Estados nacionais (Held, 1995), nós temos também um conjunto de Estados nacionais fortes que podem se opor ou simplesmente ignorar a dinâmica política pós-nacional, tal como os Estados Unidos fizeram com o tratado Anti-Minas e com o Protocolo de Kyoto.

A questão das assimetrias no recente processo de globalização recoloca a nível internacional uma questão presente no debate político dos séculos XIX e XX: a da relação entre regulação e emancipação (Santos, 2000). A primeira modernidade foi um momento de tensão entre essas duas categorias, a primeira delas identificada com as formas de controle sobre o mercado, o estado e a sociabilidade e a segunda identificada com os potenciais emancipatórios identificados pelos atores sociais na primeira modernidade. Uma categoria da moderna ciência social esteve fortemente ligada, desde a mais tenra modernidade, ao processo de emancipação: a categoria de espaço público (Habermas, 1989; Fraser, 1989, 1997; Thompson, 1995; Avritzer, 2000, 2002). Essa categoria, entendida na sua forma plural $^{2}$ como a maneira através da qual diversos atores sociais criaram formas de sociabilidade pública e questionaram em público as diferentes formas de dominação política dos trabalhadores, das mulheres, das minorias raciais e das maiorias coloniais, cumpriu um papel central em criar na primeira modernidade um duplo do Estado e do mercado. Esse duplo foi um espaço público no qual a idéia de igualdade e solidariedade foi trabalhada informalmente por diversos tipos de atores sociais que passaram a exigir formas de limitação do mercado e do Estado e reivindicar um conjunto de direitos vinculados a uma nova condição e/ou identidade. A questão central do ponto de vista heurístico é que, uma vez que a ação dos atores sociais no espaço público passou a adquirir hegemonia, a limitação do Estado e do mercado e o reconhecimento de direitos tornaram-se estratégias efetivas de emancipação. Esse fato deve-se a apenas uma característica da primeira modernidade, qual seja, a efetividade da forma regulação enquanto duplo da emancipação, ou seja, deveu-se ao fato de que os Estados modernos tiveram capacidade de enforcement de uma tradição de direitos e de limitação do mercado dentro do escopo geográfico político.

Este artigo tem como objetivo tratar o recente processo de globalização do ponto de vista da relação entre regulação e emancipação. O meu argu-

\footnotetext{
2 Jürgen Habermas foi o autor que primeiro resgatou a categoria de esfera pública nas ciências sociais contemporâneas. No entanto, a definição habermasiana de espaço público tendeu a privilegiar o que se convencionou chamar de públicos homogêneos (Fraser, 1997). Hoje diversos autores recuperaram a noção de público enquanto públicos plurais (Thompson, 1995; Melucci, 1996; Avritzer, 2002). É a essa tradição que estaremos nos referindo nesse trabalho.
} 
mento principal será o de que o processo de globalização muda a relação entre essas duas categorias e exige a introdução de um terceiro elemento que denominarei de não-regulação. A minha tese não é a de que a não regulação constitui uma característica completamente nova na modernidade e sim de que a forma como a hegemonia no espaço político globalizado ocorre no começo do século XXI consiste em uma combinação entre super-regulação e não regulação, combinação essa que adquire características completamente novas. A segunda questão que será tratada nesse trabalho é: em que medida os novos espaços públicos globais que estão surgindo na modernidade tardia podem fazer frente a esses espaços globais não regulados.

2. A questão da relação entre regulação e emancipação foi introduzida como forma de entendimento da modernidade por Boaventura de Sousa Santos. $\mathrm{O}$ autor da Crítica da razão indolente entende a modernidade enquanto um processo de diferenciação. Para ele, dois tipos distintos de diferenciação ocorreram na modernidade: a diferenciação entre Estado, mercado e comunidade e a diferenciação entre três tipos de racionalidade: a cognitivo-instrumental, a prático-moral e a estético-expressiva. ${ }^{3}$ Para Boaventura de Sousa Santos, o primeiro eixo da diferenciação estaria ligado ao eixo da regulação e seria baseado na idéia de obrigação, enquanto o segundo eixo estaria ligado à idéia de emancipação:

O princípio do Estado consiste na obrigação política vertical entre cidadãos e Estado. O princípio do mercado consiste na obrigação política horizontal, individualista e antagônica entre os parceiros de mercado. O princípio da comunidade consiste na obrigação política horizontal solidária entre os membros da comunidade e entre associações. (Santos, 2000: 50)

\footnotetext{
${ }^{3}$ O entendimento da modernidade como um processo de diferenciação de três esferas axiológicas remete a Max Weber, ainda que Weber de saída já tenha colocado em questão os potenciais emancipatórios dessas esferas e trabalhado com a idéia de fragmentação. Em A ciência como vocação Weber irá tratar da oposição entre a ciência, o direito e a moral pretendendo mostrar que cada uma dessas esferas possui um critério próprio de racionalidade em oposição ao das outras esferas. Para Weber, "alguma coisa pode ser verdadeira, ainda que não seja sagrada, bela e nem boa [...] esses casos [de conflito entre as diferentes ordens valorativas] são os mais elementares na luta em que os deuses das várias ordens e valores se estão empenhando" (Weber, 1946: 148). O argumento weberiano é de que apenas a ciência se preserva na luta entre as várias esferas de valores. Santos retoma o diagnóstico weberiano atribuindo à ciência um carácter de dominação do senso comum. Para uma crítica à posição de Weber sobre o diagnóstico do politeísmo das ordens de valor, cf. Avritzer, 1996.
} 
A originalidade da concepção de modernidade proposta por Santos irá se manifestar na forma como o problema da dominação é transferido do campo do mercado e do Estado para o campo da ciência e do direito. Para Santos, não é no eixo Estado, mercado e comunidade onde os problemas da modernidade irão se manifestar, mas sim no eixo ciência e direito. Nesse eixo, duas categorias que originalmente estavam destinadas no projeto original da modernidade a se constituírem como categorias emancipatórias, ${ }^{4}$ se tornaram eixos a partir dos quais a regulação se processa. Tanto a ciência quanto o direito foram se tornando eixos de regulação na medida em que a modernidade se desenvolvia: "promovidos pela rápida conversão da ciência em força produtiva, os critérios científicos de eficiência e eficácia logo se tornaram hegemônicos, ao ponto de colonizarem gradualmente os critérios racionais das outras lógicas emancipatórias." (Santos, 2000: 51). Desse modo, o que passamos a ter na modernidade tardia, foi a absorção do pilar da emancipação pelo pilar da regulação; mercado, ciência e direito se associam em um projeto regulativo hegemônico capaz de anular potenciais emancipatórios.

No entanto, para Boaventura de Sousa Santos, o pólo da emancipação não se esgotou. Ele continuaria presente em duas categorias, uma delas presente no pólo da regulação e a outra presente no pólo da emancipação: trata-se das categorias comunidade e racionalidade estético-expressiva. A comunidade, apesar de localizada por Santos inicialmente no pólo da regulação, em virtude das formas de obrigação entre os indivíduos por ela gerada, retêm, ao longo da modernidade, potenciais de emancipação:

$[\mathrm{P}]$ orque é uma representação aberta e incompleta, a comunidade é ela própria dificilmente representável [...] e os seus elementos constitutivos são também eles abertos e inacabados [...]. Têm, contudo, uma característica comum: todos resistiram à diferenciação técnico-científica através da qual a racionalidade cognitivo-instrumental da ciência moderna colonizou os outros princípios da regulação: o mercado e o Estado.

(Santos, 2000: 75)

Ou seja, o que Santos procura apontar na modernidade é o processo através do qual Estado e mercado são subordinados à lógica da ciência, lógica essa que é de abstração do conteúdo e de criação de uma lógica da

\footnotetext{
${ }^{4}$ Certamente a ciência moderna foi vista, inicialmente, em especial, pela tradição marxiana como a categoria produtora da emancipação. Para Marx, o ato de reflexão próprio à atividade produtiva era, ao mesmo tempo, um ato de transformação e domínio da natureza. É nesse ponto que se funda boa parte do determinismo econômico e da teleologia própria ao pensamento marxiano. Cf. Avritzer, 1996.
} 
eficácia e da instrumentalização. A comunidade, por ter sido entre os três pilares da regulação o menos susceptível à regulação instrumental é o que preserva algumas categorias emancipatórias, em especial as idéias de solidariedade e de participação.

Ainda que o autor não tenha feito um esforço teórico nessa direção, é possível apontar uma série de superposições entre a forma como Santos entende o resgate da emancipação e a categoria que se convencionou denominar de espaço público. O conceito de esfera pública foi o conceito central desenvolvido pela teoria crítica na segunda metade do século XX (Habermas, 1989; Thompson, 1995; Fraser, 1997; Cohen, 1997; Bohmann, 1996; Avritzer, 2002). Ele cumpriu o papel de recuperar na modernidade temporã uma esfera de interação entre grupos, associações e movimentos, capaz de criar um terceiro caminho no interior da teoria democrática no debate entre a democracia elitista e a democracia participativa. O conceito de esfera pública introduz a possibilidade de uma relação crítico-argumentativa com a política, ao invés de uma relação diretamente participativa (Avritzer, 2002), abrindo, desse modo, a possibilidade de uma nova conexão, no interior da teoria democrática, entre racionalidade, participação e emancipação.

O conceito de esfera pública levou ao desenvolvimento de dois campos no interior da teoria social contemporânea: um primeiro campo é composto pelas teorias da sociedade civil e um segundo composto pelos movimentos sociais. Ambas as teorias, apesar dos seus diferentes enfoques, ${ }^{5}$ se baseiam na idéia do desenvolvimento no interior das sociedades modernas de uma esfera dialógica e interativa, à qual pertencem tanto os movimentos sociais quanto as associações voluntárias. A tematização de novas questões, a formação de identidade e de solidariedades capazes de aferir a validade dos reclamos morais envolvidos na política seriam a dimensão central da esfera pública entendida dessa forma. É em relação a essa forma de ação no interior do espaço público que a democracia tem sido abordada no campo da

\footnotetext{
${ }^{5}$ Existem diferenças analíticas importantes entre as teorias dos movimentos sociais e as teorias da sociedade civil. O pano de fundo dessas diferenças está relacionado com o fato que cada uma das teorias lida com momentos diferentes da ação coletiva. As teorias dos movimentos sociais enfatizam aqueles momentos da vida social nos quais as relações sociais ainda não se cristalizaram nas estruturas sociais. Questões como a formação de identidades, de solidariedades e a tematização de novas questões tornam-se as dimensões centrais das teorias dos movimentos sociais. Já no caso das teorias da sociedade civil, elas enfatizam um momento posterior da ação coletiva no qual formas de ação coletiva se institucionalizam em redes associativas, redes essas que através de fluxos de comunicação e influência alcançam o sistema político. As teorias da sociedade civil enfatizam, nesse caso, a autonomia legal das formas associativas e as práticas democráticas internas às associações civis (Avritzer, 2000).
} 
teoria crítica, enquanto uma teoria que aposta na capacidade democratizada dos movimentos sociais e dos atores da sociedade civil entendidos como parte de um espaço emancipatório interativo e, portanto, livre das regulações próprias ao mercado e ao Estado moderno.

Podemos, desse modo, perceber o papel do espaço público na constituição de um pólo emancipatório e não regulador na primeira modernidade. Esse pólo foi constituído pelos atores sociais cujas condições coletivas de vida não foram tematizadas, em um primeiro momento, por uma forma liberal e individualizante de direito. Os trabalhadores seriam o primeiro grupo nessa situação, na medida em que nem o direito privado nem o direito estatal os reconheceram como sujeitos de direitos; as mulheres também estiveram claramente nessa situação na medida em que os problemas envolvidos em uma esfera privada desigual permaneceram não tematizados pelo direito. Cada um desses grupos utilizou a esfera pública para apresentar uma condição e reclamar um conjunto de direitos que estavam além da ordem liberal individualizante estabelecida na primeira modernidade.

No entanto, o ponto sobre o qual gostaria de chamar a atenção para estabelecer um contraste entre uma modernidade fundamentalmente localizada no interior dos Estados nacionais e uma modernidade tardia globalizada é o do papel da instância política estatal no processo de reconhecimento de direitos. O que me parece relevante aqui é que, ainda que movimentos sociais e associações civis tenham atuado em um espaço público constituído por práticas informais, a forma de implantação desses direitos se deu através da sua incorporação em um direito estatal cuja efetividade não estava em questão. Sendo assim, a característica central das formas emancipatórias na primeira modernidade seria a sua capacidade de fazer com que a forma estatal dominante, o Estado moderno, reconhecesse uma condição de exclusão e tornasse a sua incorporação na normatividade existente uma realidade cuja efetividade não estaria em questão. O meu argumento na seção seguinte desse artigo será o de que no mundo globalizado essa dimensão não está mais presente.

3. O atual processo de globalização não é um processo homogêneo. Pelo contrário, ele é um processo de globalização econômica, política e cultural que obedece a ritmos e lógicas distintas em cada uma dessas esferas. Nesta seção nós pretendemos tratar do problema da globalização a partir de três óticas: da ótica da constituição de uma institucionalidade pós-nacional reguladora; da ótica da constituição de mecanismos de pressão próprios ao espaço público a nível internacional; e da ótica da constituição de espaços políticos pós-nacionais não regulados. 
A globalização econômica opera a partir de uma complementaridade entre

[a] autonomia dos mercados e os «Estados facilitadores» orientada para a liberalização, a privatização, a desregulamentação da economia, a retração dos gastos com bens públicos e dos encargos com o bem estar social, a plena mobilidade dos capitais em simultâneo com um estrito controlo internacional e uma total flexibilidade nacional. (Pureza, 2001: 240)

A globalização econômica, assim entendida, é claramente uma nova forma de relação entre Estado e mercado. Por um lado, passa a haver um conjunto de atividades econômicas que se desenrolam a nível global e, por outro lado, a idéia westfaliana de uma ordem internacional hobbesiana é substituída por um conjunto de instituições reguladoras a nível internacional. Desde o pós-segunda guerra mundial foi constituído um conjunto de instituições técnicas e políticas a nível global, das quais vale a pena mencionar, entre as técnicas, a União Postal Universal, a União Internacional de Telecomunicações e a Organização Meteorológica Mundial. Entre as organizações internacionais de fundo político vale a pena mencionar o Banco Mundial, o Fundo Monetário Internacional e um conjunto de outras organizações internacionais ligadas às Nações Unidas. Assim, a partir do pós-guerra, a assimetria que já existia entre Estados fortes e Estados fracos assume uma nova forma:

[...] a soberania dos Estados mais fracos passa a estar ameaçada, não tanto pelos Estados mais poderosos, como costumava ocorrer, mas sobretudo por agências financeiras internacionais e outros actores transnacionais privados, tais como as empresas multinacionais. (Santos, 2001: 44)

O problema em relação a essas organizações é que elas exercem um papel regulador externo, isto é, elas não têm capacidade de enforcement e sim capacidade de pressão. Desse modo, estabelece-se uma assimetria entre os países que não são capazes de resistir à agenda das organizações internacionais e os países que nem ao menos necessitam recorrer a tais agências. Por um lado, temos os países que não têm alternativa a não ser aceitar os programas de ajustamento estrutural do Fundo Monetário Internacional, que passam a constituir uma forma de "auto-regulação" imposta de fora. De outro lado, temos países como os Estados Unidos, que ainda conseguem se auto-regular através dos mecanismos clássicos de uma economia nacional, devido à hegemonia da sua própria moeda. Nesse sentido, ao 
mesmo tempo que temos a emergência de uma institucionalidade pós-nacional, tal institucionalidade apresenta assimetrias profundas (Held, 1995).

O segundo movimento que nós temos enquanto resultado do atual processo de globalização é a constituição de um conjunto de associações que operam a nível internacional e de um conjunto de atividades que ocorrem nesse espaço. $\mathrm{O}$ associativismo, assim como os movimentos sociais, são formas de ação coletiva que tiveram suas origens fortemente ligadas a tradições culturais e formas de luta no interior do Estado nacional. Tal fato é verdadeiro no que diz respeito a alguns dos movimentos e associações mais importantes da primeira modernidade, como o movimento operário, o movimento feminista, o movimento de direitos civis norte-americano. A dimensão pós-nacional dos movimentos da sociedade civil é um fenômeno recente ligado à características do próprio processo de globalização: o aumento do uso da Internet por uma fatia da população que atinge um quarto do seu total nos principais países desenvolvidos; o aumento da percentagem de pessoas que se movimentam para além dos seus Estados nacionais de origem que, nos principais países da Europa, atinge o índice de $1 \%$ por ano (Anheir et al., 2001: 8). Finalmente, houve também na última década um aumento significativo de questões que passaram a adquirir uma dimensão pós-nacional, tal como tem sido o caso da questão dos direitos humanos e do meio ambiente.

Todos esses processos, conjuntamente, levaram a um aumento significativo no número de associações civis transnacionais ou, para utilizar um dos termos da literatura hegemônica sobre o assunto, de INGO's (organizações não governamentais internacionais), acelerando assim dois processos: a constituição de uma agenda de reuniões internacionais institucionalizadas patrocinadas pelas Nações Unidas e a constituição de uma arena de fóruns e movimentos não institucionalizados.

A constituição de um conjunto de fóruns internacionalizados teve como objetivo acelerar a tematização de questões relevantes. Chamo aqui a atenção para as reuniões internacionais patrocinadas pelas Nações Unidas. Se, por um lado, é correto afirmar que as Nações Unidas sempre realizaram reuniões mundiais, por outro lado, os anos 90 marcaram uma mudança de qualidade dessas reuniões devido à sua intensificação e devido ao florescimento de eventos paralelos a essas reuniões. As principais conferências organizadas pelas Nações Unidas nos anos 90 foram: a Conferência do Rio em 1992 sobre meio ambiente e desenvolvimento, a Conferência de Viena sobre direitos humanos em 1993, a Conferência do Cairo sobre população em 1994 e as Conferências de Copenhague e Beijing em 1995. Em todas 
essas conferências houve uma acentuada participação paralela de ONG's, culminando com a participação de milhares de ONG's na Conferência de Beijing sobre Direitos das Mulheres (Pianta, 2001: 174). Pode-se observar, no caso das reuniões nas Nações Unidas, uma tentativa de introduzir um elemento das esferas públicas nacionais em uma arena internacional: em primeiro lugar, as reuniões das Nações Unidas foram baseadas na idéia da tematização de questões candentes, uma forma de ação que ecoa as formas de ação dos movimentos da sociedade civil na esfera pública (Melucci, 1996). Em segundo lugar, o objetivo dessas reuniões foi a criação de consenso pós-nacional acerca de determinados temas, processo esse que utilizou dois mecanismos próprios à tradição dos movimentos da sociedade civil: a tradição declaratória (que é própria das instâncias políticas sem a efetividade do Estado moderno) e as formas de interação face-a-face.

O fim da década dos 90 marcou também o surgimento de um conjunto de movimentos e de fóruns internacionais no campo do que podemos denominar de globalização contra-hegemônica (Santos, 2001). Movimentos como o movimento anti-globalização e sua forte presença nas reuniões de Seattle e Gênova passam a representar uma grande novidade no campo pós-nacional na medida em que passa a haver atores internacionais que se reúnem e protestam simultaneamente a realização de reuniões de organizações como a OMC ou o FMI. Uma novidade ocorreu em Seattle: a realização de uma manifestação internacional pública com o objetivo de, através da mobilização, impedir que a nova rodada de liberalização do OMC ocorresse. Vê-se aqui, mais uma vez, a operação de um elemento próprio dos espaços públicos nacionais: a agregação de atores sociais com o objetivo de impedir a ação de atores antagônicos, forma clássica de ação de movimentos como o operário e o feminista na primeira metade do século XX.

Um segundo momento no processo de constituição de espaços públicos pós-nacionais é o constituído pelo Fórum Social Mundial, ou Fórum de Porto Alegre. O Fórum Social Mundial é uma reunião anual sediada em Porto Alegre organizada por um conjunto amplo de organizações nacionais e internacionais da sociedade civil, entre as quais caberia destacar: a Abong, Associação Brasileira de ONG's, a ATTAC, Ação pela Tributação das Transações Financeiras em Apoio aos Cidadãos, Comissão Brasileira de Justiça e Paz da CNBB, Conferência Nacional dos Bispos do Brasil, Civis, Associação Brasileira de Empresários pela Cidadania. Participam também movimentos sindicais e rurais importantes no Brasil, tais como a Central Única dos Trabalhadores e o Movimento dos Sem Terra. Podemos aqui perceber que o Fórum Social Mundial é uma tentativa de articulação de 
entidades locais que lutam contra a assim chamada globalização hegemônica com entidades internacionais que buscam democratizar o processo de globalização, como é o caso da ATTAC.

Três elementos centrais fazem parte da proposta do Fórum e são responsáveis pelo seu amplo apelo público e mediático: em primeiro lugar, o fato de ele se ancorar em uma experiência local de democracia participativa e justiça social, a assim chamada experiência de Porto Alegre (Santos, 2002; Avritzer, 2002); A experiência de Porto Alegre, uma experiência participativa e distributiva em um país do Sul, mostra os potenciais de uma forma mais democrática e distributiva de gestão pública que sensibiliza atores sociais nos países do Sul e do Norte. Em segundo lugar, vale a pena mencionar a capacidade do Fórum Social Mundial de sistematizar uma temática progressista de democratização da globalização, temática essa que envolve questões como o desenvolvimento sustentável, a criação de mecanismos democráticos de gestão global e a constituição de bases para um comércio internacional mais justo. Em terceiro lugar, o fato de o Fórum ser um momento de interação entre um conjunto de atores locais e globais com o objetivo específico de se contrapor ao, mas também de influenciar o encontro de referência do processo de globalização hegemônica que é o Fórum Econômico Mundial realizado na cidade Suíça de Davos. É possível perceber que o Fórum Social Mundial também expressa características das formas de ação no espaço público presentes na primeira modernidade, na medida em que consegue reunir em um mesmo local um conjunto diverso e plural de atores com o objetivo de protestar contra uma reunião organizada pelas forças hegemônicas da globalização e de elaborar uma agenda paralela de globalização. Temos, portanto, em cada um dos três exemplos mencionados acima, o das reuniões paralelas aos Fóruns das Nações Unidas, o do Movimento Anti-Globalização e o do Fórum Social Mundial, a perspectiva de constituição de uma arena pública pós-nacional baseada na extensão para o nível internacional de características do espaço público nacional. Seriam o movimento anti-globalização e o Fórum Social Mundial evidências de que poderíamos pensar uma forma de espaço público pós-nacional semelhante ao espaço público nacional?

A resposta a essa questão me parece negativa por um motivo principal, que eu denominaria a emergência dos paraísos políticos, isto é, de uma forma de ação política não regida pela normatividade pós-nacional e que se desenvolve em espaços não regulados. A partir da emergência de formas diversas de ação social em oposição ao atual processo de globalização, passaram a surgir locais nos quais a normatividade internacional da modernidade tardia não se aplica ou países que utilizando o desequilíbrio das rela- 
ções internacionais se recusam a aceitar os tratados resultantes das conferências das Nações Unidas. Abaixo enumeramos o que podemos denominar de três evidências nessa direção.

O primeiro tipo de ação está relacionada à recusa dos Estados Unidos em aderirem a tratados internacionais que detêm amplo consenso pós-nacional. Dois tratados recentes, o Tratado Anti-Minas e o Protocolo de Kyoto apontam nessa direção. O Tratado Anti-Minas é resultado do que denominamos acima de formas de ação pública semelhantes àquelas próprias da primeira modernidade. Ele se iniciou por ocasião de uma campanha pública lançada em 1992 e que reuniu 1.300 Organizações Não-Governamentais de diversas áreas. A Campanha passou a tematizar a questão da eliminação das minas terrestres no plano internacional, utilizando atores e personagens públicas e adquirindo um apoio crescente. Em 1997, em Ottawa, 122 países assinaram um tratado banindo o uso de minas terrestres. Em 1997 os organizadores da Campanha foram agraciados com o Prêmio Nobel da Paz (ICBL, 2002). O exame do Tratado Anti-Minas revela, no entanto, as assimetrias da normatividade internacional emergente e a facilidade de recorrer à não regulação. $\mathrm{Na}$ medida em que o texto nomeia o secretariado geral da Nações Unidas como depositário da Convenção, mas não prevê nenhum tipo de sanção contra aqueles que se decidam pela não adesão, ele abre espaço para a não adesão do país hegemônico da ordem globalizada se ele assim o desejar. De fato, foi o que aconteceu com o governo Clinton anunciando a adesão ao Tratado Anti-Minas em 2006 e o governo de Georg W. Bush anunciando a não adesão ao tratado (ICLB, 2002).

Uma postura semelhante ocorreu na tentativa de se estabelecer um limite para emissão de gases poluentes, conhecido como Protocolo de Kyoto. O Protocolo de Kyoto é o resultado das políticas da Nações Unidas para o controle de mudanças climáticas, uma política que teve início nos anos 90 através de um Comitê Intergovernamental que conduziu negociações ratificadas na Conferência do Rio de Janeiro de 1992. Desde então, o acordo foi ratificado por 186 países, se aproximando do que, na terminologia das Nações Unidas se denomina “universal membership.” Para avançar a implementação da convenção sobre mudanças no clima ocorreram uma série de novas negociações, que conduziram ao Protocolo de Kyoto em 1997. Esse é o Protocolo que a administração Bush se recusa a assinar, mais uma vez colocando em pauta o problema da capacidade de enforcement de uma normatividade internacional (Sanger, 2001). Nesse primeiro caso, o problema não é o da ausência de uma normatividade internacional emergente e sim de um super-ator que não é influenciado por essa nova normatividade e cuja não adesão compromete os objetivos dela. 
O segundo tipo de ação no sentido de uma ordem internacional não normalizada está relacionado com a recente reunião do OMC em Doha. À medida que as reuniões da Organização Mundial do Comércio foram sendo afetadas pela mobilização de atores sociais, o primeiro tipo de resposta baseada na adesão a uma normatividade paralela surgiu: a transferência da reunião da OMC para Doha, no Qatar. Nessa reunião de ministros, realizada em um pequeno Emirato, as organizações internacionais, os grupos de protesto e até mesmo a mídia internacional tiveram dificuldade em acompanhar os acontecimentos através da sua presença no local. Como relata Walden Bello, a delegação americana estava conectada a um conjunto de navios de guerra que operam no Golfo Pérsico e que estavam de prontidão. Temos, assim, uma primeira forma de manifestação da relação entre uma normatividade internacional emergente e o acesso privilegiado a espaços paralelos, como o dos Emiratos Árabes. Nessa nova relação, utiliza-se o espaço de um Estado nacional que não chegou a aderir plenamente ao processo de democratização próprio aos Estados nacionais da primeira modernidade para se criar uma barreira às formas de desenvolvimento de um espaço público internacionalizado. Esse é o primeiro motivo para se pensar que uma abordagem sobre a emergência de espaços públicos internacionalizados tem que envolver a relação entre regulação, emancipação e não regulação.

Um terceiro exemplo torna a questão ainda mais relevante que é a decisão dos Estados Unidos, depois do 11 de Setembro, de recorrer a Tribunais Militares para julgar pessoas acusadas de terrorismo e prisioneiros da $\mathrm{Al}$ Qaeda na Guerra do Afeganistão. Mais uma vez, o que está em jogo aqui é a tentativa de um país signatário das principais convenções internacionais de direitos humanos de não pautar as suas ações por essa normatividade. Nesse caso, os julgamentos de terroristas da Al Qaeda se dariam fora das regras do direito internacional e da Convenção de Genebra, através da criação de um espaço internacional não regulado por regras internacionais. Acrescente-se a tal postura a tentativa de não atribuir aos prisioneiros da guerra do Afeganistão os direitos estabelecidos pela convenção de Genebra (Seelye, 2002) e podemos perceber, também nesse caso, a emergência de uma terceira forma de ação internacional não pautada pela vigência da normatividade internacional existente.

Temos, assim, três padrões emergentes de não regulação a nível internacional: o primeiro padrão é o de negar às convenções internacionais que são resultado de um processo longo de interação face-a-face, tais como o Tratado Anti-Minas e o Protocolo de Kyoto, o carácter de um normatividade com efetividade. A forma da negação é a recusa pelo país hegemônico 
em assinar essas convenções, um elemento do processo de criação de uma normatividade internacional que não se vê presente ao nível nacional no qual as maiorias são suficientes para a criação de leis. O segundo elemento é a associação entre uma normatividade local democrática e uma normatividade local não democrática, no sentido de fortalecer a nível internacional uma posição insustentável na maior parte dos Estados nacionais democráticos. É o caso da reunião da OMC em Doha. Nesse caso, utiliza-se a normatividade pré-moderna de um Emirato Árabe para impedir a atuação do movimento anti-globalização, o que não foi possível fazer nem em Seattle nem em Gênova. Nesse caso, temos também uma estratégia que não foi possível de ser adotada pelos Estados nacionais na medida em que eles não puderam nem suprimir as manifestações públicas nem transferir o local de reunião das instituições estatais. Por fim, temos uma terceira estratégia, que é a defesa de espaços internacionais nos quais a normatividade internacional não pode vigorar, como é o caso dos julgamentos dos responsáveis por terrorismo em navios de guerra dos Estados Unidos. Os três elementos conjuntamente colocam com força o problema da não-regulação na ordem pós-nacional emergente. $\mathrm{Na}$ parte final desse artigo, tentaremos apontar algumas conseqüências teóricas dessa análise.

4. O entendimento da modernidade como uma relação entre regulação e emancipação tem como pano de fundo a democratização dos Estados nacionais europeus. Durante esse processo, surgiram públicos informais cuja influência constitui um fator decisivo de democratização e de cidadanização na Europa e posteriormente nos Estados Unidos. Esses públicos foram baseados em formas de ação coletiva tais como os movimentos sociais, as associações civis, as grandes manifestações públicas como formas de apresentação de demandas e a possibilidade sempre presente de ações que interrompessem as atividades do governo (Tilly, 1986). Em todos os casos, o Estado moderno foi democratizado por essas formas de ação devido à relação que elas foram capazes de constituir entre legitimidade e efetividade. A legitimidade esteve ligada à capacidade de convencimento dessas formas de ação e sua influência sobre o sistema político. A efetividade ao fato de o Estado nacional ter incorporado demandas pela cidadania ou pela limitação do exercício do poder econômico e tornado essas demandas a lei da cidade.

Este artigo teve como objetivo argumentar que é insuficiente mostrar a existência de paralelismo entre as formas públicas de ação no interior do Estado nacional e as formas públicas de ação pós-nacional. Apesar de ser possível mostrar que as formas de interação face-a-face, as manifestações 
simultâneas à realização de eventos e a constituição de fóruns são possíveis de ocorrer a nível pós-nacional, mostramos também que a reação a essas formas de ação coletiva assume uma nova feição. Atribuímos essa assimetria ao problema da não regulação que, como mostramos acima, possui uma dimensão não presente no processo de construção dos Estados nacionais: a sua centralidade nas estratégias das forças políticas hegemônicas. No processo de construção dos estados nacionais e sua posterior democratização, o campo da não regulação foi o campo das forças pré-modernas solapadas pela própria construção do Estado nacional. Assistimos hoje a um novo balanço de forças que recoloca o problema da relação entre regulação e emancipação como dois conceitos a serem completados por um terceiro, o da não regulação. Qual seria a relação, nesse caso, entre a emancipação e a não regulação?

A nosso ver, a criação de uma normatividade pós-nacional que faz parte dos objetivos de uma emancipação auto-limitada terá de recorrer a duas arenas que no processo de construção dos estados nacionais estiveram no pólo da regulação: a da institucionalização e da efetividade. Os movimentos emancipatórios da modernidade assumiram corretamente essas dimensões ou como dadas ou como não problemáticas. No processo de democratização da globalização essas duas dimensões passam a fazer parte de um campo emancipatório na medida em que a dominação passa a estar ligada à procura da não regulação pelos atores econômicos e políticos hegemônicos. Uma nova normatividade pós-nacional terá assim de recorrer à tentativa de institucionalizar a sua agenda emancipatória de forma a torná-la efetiva. Nesse sentido, cabe às novas instituições globalizadas o papel de se tornarem tão experimentais como os movimentos sociais da modernidade, sem abdicar da tentativa de serem tão efetivas quanto os Estados modernos.

\section{Referências Bibliográficas}

Amheir, Helmut; Marlies, Glasius; Kaldor, Mary (2001), «Introducing Global Civil

Society», in H. Amheir et al., Global Civil Society. Oxford: Oxford UP.

Avritzer, Leonardo (1996), A moralidade da democracia. São Paulo: Perspectiva.

Avritzer, Leonardo (2000), «Entre o diálogo e a reflexividade: A modernidade tardia e mídia», in L. Avritzer; J.M. Domingues, Teoria social e modernidade no Brasil. Belo Horizonte: UFMG.

Avritzer, Leonardo (2002), Democracy and the Public Space in Latin America. Princeton: Princeton UP.

Bohman, James (1996), Public Deliberation. Cambridge: MIT Press. 
Cohen, J. (1997), «Deliberation and Democratic Legitimacy», in James Bohman; William Rehg, Deliberative Democracy. Cambridge, Mass.: MIT Press.

Fraser, Nancy (1989), Unruly Practices: Power, Discourse and Gender in Contemporary Social Theory. Minneapolis: University of Minnesota Press.

Fraser, Nancy (1997), Justice Interruptus. London: Routledge.

Habermas, Jürgen (1989), The Structural Transformation of the Public Sphere: An Inquiry into a Category of Bourgeois Society. Cambridge, Mass.: MIT Press.

Held, David (1995), Democracy and the Global Order. Cambridge: Polity Press.

Hirst, Paul; Thompson, Grahame (1995), Globalization in Question. Cambridge: Polity Press.

ICLB (2002), International Campaign to Ban Land Mines. Disponível em: <www.iclb.org>.

Melucci, Alberto (1996), Challenging Codes: Collective Action in the Information Age. Cambridge: Cambridge UP.

Pianta, M. (2001), «Parallel Summits of Global Civil Society», in H. Amheir et al., Global Civil Society. Oxford: Oxford UP.

Pureza, José Manuel (2001), «Para um internacionalismo pós-vestefaliano», in Boaventura de Sousa Santos (org.), Globalização: Fatalidade ou utopia?. Porto: Afrontamento, 233-254.

Robertson, Roland (2000), Globalização: Teoria social e cultura global. Petrópolis: Vozes.

Sanger, D. (2001), «Bush Will Continue to Oppose Kyoto Pact on Global Warming», New York Times.

Santos, Boaventura de Sousa (2000), A crítica da razão indolente. São Paulo: Cortez.

Santos, Boaventura de Sousa (2001), «Os processos de globalização», in B. S. Santos (org.), 31-106.

Santos, Boaventura de Sousa (2002), «O orçamento participativo em Porto Alegre: Para uma democracia redistributiva», in B. S. S. (org.), Democratizar a Democracia. Rio de Janeiro: Record.

Seelye, D. (2002), «A Nation Challenged», New York Times.

Tilly, Charles (1986), The Contentious French. Cambridge: Harvard UP.

Thompson, John (1995), The Media and Modernity. London: Polity Press.

Weber, Max (1946), From Max Weber: Essays in Sociology. Org. H. H. Gerth; C. Wright Mills. New York: Oxford UP. 